Faculty of Pharmaceutical Sciences, University of Tokyo

Bunkyo-ku, Tokyo

Received March 27, 1971
Masao INOUE

HiKoya HaYATSU

\title{
Stereostructure of Grayanotoxin VIII, IX, X, and XI. Toxins of Leucothoe grayana
}

From the leaves of Leucothoe grayana Maxamowicz (Ericaceae), a famous poisonous shrub in Japan, seven toxic diterpenoids, grayanotoxin I, II, III, ${ }^{1,2)}$ IV, ${ }^{3)} V^{, 3,4)}$ VI, and VII, () have been isolated. Further survey of the toxic constituents of the leaves has led to the isolation of four novel diterpenoids for which the terms grayanotoxin VIII, IX, X, and XI (G-VIII, G-IX, G-X, and G-XI) are proposed.

G-VIII, $\mathrm{C}_{20} \mathrm{H}_{30} \mathrm{O}_{4}, \mathrm{mp} 190-193^{\circ}$, was revealed ${ }^{5)}$ to have two tertiary methyls $(1.06,1.49$ ppm), two vinylidenes $\left(1626,887 \mathrm{~cm}^{-1}, 4.93-5.11 \mathrm{ppm}\right)$, and hydroxyls $\left(3350 \mathrm{~cm}^{-1}\right)$ in which three are secondary $(3.83,4.31,4.39 \mathrm{ppm})$. On acetylation G-VIII gave the diacetate (V). Analysis of the nuclear magnetic resonance (NMR) spectra of G-VIII and its acetate (V) indicated that the structure of G-VIII resembles that of G-VII (VI). ${ }^{4}$ ) Indeed, the spectral properties of G-VIII can be well rationalized provided that the 15-ene system in G-VII is replaced by a 16 -ene system in G-VIII. In order to confirm this assumption, G-II (VII) in dioxane was heated under reflux in the presence of cupper sulfate to yield two dehydration products, one being identified as G-VIII and the other identified as G-VII (VI). On the basis of the above evidence, it is established that G-VIII is represented by formula I.

G-IX, $\mathrm{C}_{22} \mathrm{H}_{32} \mathrm{O}_{5}, \mathrm{mp} 151-152^{\circ}$, was shown ${ }^{5)}$ to possess two tertiary methyls $(1.01,1.24$ ppm), a vinyl methyl $(1.71 \mathrm{ppm})$, a vinylidene $\left(1625,891 \mathrm{~cm}^{-1}, 4.94,5.08 \mathrm{ppm}\right)$, a vinyl hydrogen $(5.13 \mathrm{ppm})$, a secondary O-acetyl $\left(1730,1240 \mathrm{~cm}^{-1}, 2.06,5.47 \mathrm{ppm}\right)$, and hydroxyls $\left(3370 \mathrm{~cm}^{-1}\right)$, two of which are secondary $(3.52,3.63 \mathrm{ppm})$. Then alkaline hydrolysis of G-IX was carried out to yield deacetyl-G-IX which was identified as G-VII (VI). The C-14 hydrogen signal in the NMR spectrum of G-IX occurs at a lower-field region (5.47 ppm), indicating that the C-14 hydroxyl is acetylated. Therefore, G-IX is concluded to have the stereostructure II.6)

$\mathrm{G}-\mathrm{X}, \mathrm{C}_{\mathbf{2 0}} \mathrm{H}_{32} \mathrm{O}_{5}, \mathrm{mp} 165.5-166.5^{\circ}$, was indicated ${ }^{5)}$ to have two tertiary methyls $(1.00,1.22$ $\mathrm{ppm})$, two vinylidenes $\left(1630,883 \mathrm{~cm}^{-1}, 4.87,4.97,5.11 \mathrm{ppm}\right)$, a secondary O-acetyl $(1730$, $\left.1235 \mathrm{~cm}^{-1}, 2.05,5.11 \mathrm{ppm}\right)$, and hydroxyls $\left(3340 \mathrm{~cm}^{-1}\right)$, two of which are secondary $(3.51,3.61$ $\mathrm{ppm})$. G-X was then subjected to alkaline hydrolysis furnishing deacetyl-G-X which was found identical with G-VIII (I). Since the C-14 hydrogen signal in the NMR spectrum of $\mathrm{G}-\mathrm{X}$ discloses a lower-field shift $(5.11 \mathrm{ppm})$, the $\mathrm{C}-14$ hydroxyl is acetylated. It follows that G- $\mathrm{X}$ is shown as III.6)

1) cf. H. Kakisawa, T. Kozima, M. Yanai, and K. Nakanishi, Tetrahedron, 21, 3091 (1965).

2) H. Hikino, M. Ogura, T. Ohta, and T. Takemoto, Chem. Pharm. Bull. (Tokyo), 18, 1071 (1970).

3) T. Okuno, N. Hamanaka, H. Miyakoshi, and T. Matsumoto, Tetrahedron, 26, 4765 (1970).

4) H. Hikino, N. Shoji, S. Koriyama, T. Ohta, Y. Hikino, and T. Takemoto, Chem. Pharm. Bull. (Tokyo), 18, 2357 (1970).

5) NMR spectra of G-VIII and G-XI were measured in $\mathrm{C}_{5} \mathrm{D}_{5} \mathrm{~N}$ and those of C-IX and G-X recorded in $\mathrm{CDCl}_{3}$.

6) Apparently the same substances have been recently isolated from Rhododendron ponticum LiNNÉ (S. von Kürten, P. Pachaly, F. Zymalkowski, and G. Snatzke, Ann., 741, 142 (1970)). 


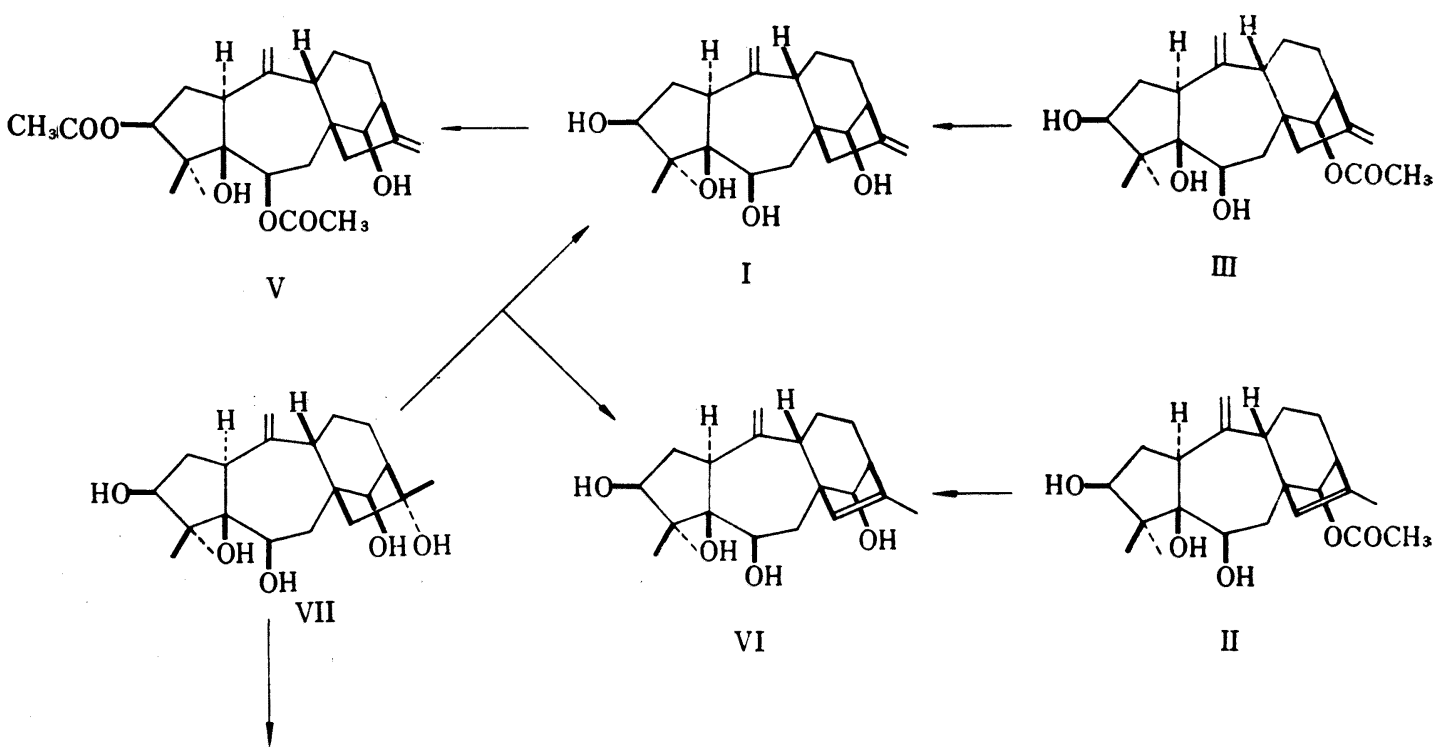

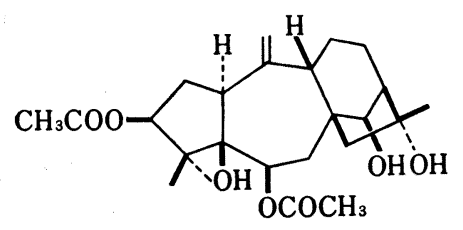

$\mathrm{X}$

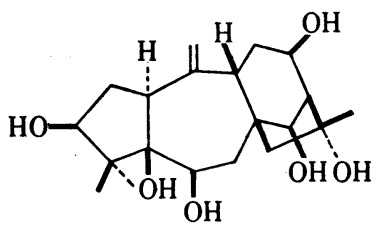

IV

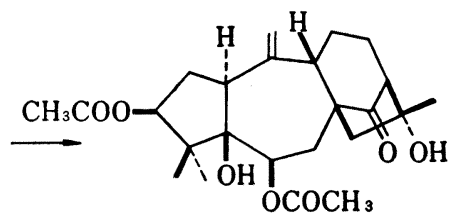

$\mathrm{XI}$

G-XI, $\mathrm{C}_{20} \mathrm{H}_{32} \mathrm{O}_{6}, \mathrm{mp} 176-177^{\circ}$, was shown ${ }^{5)}$ to contain two tertiary methyls $(0.94,1.43$ $\mathrm{ppm})$ a tertiary methyl on a hydroxyl-bearing carbon $(2.01 \mathrm{ppm})$, a vinylidene $(3120,1633$, $\left.891 \mathrm{~cm}^{-1}, 5.20,5.25 \mathrm{ppm}\right)$, hydroxyls $\left(3300 \mathrm{~cm}^{-1}\right)$, four of which are secondary $(3.90,4.30,4.45$, $4.56 \mathrm{ppm})$. Analysis of the NMR spectrum with the aid of double resonance experiments revealed the presence of the partial structure A in G-XI. Inter alia, intramolecular nuclear Overhauser effects were observed between the C-1 and C-6 hydrogens, the C-1 and C-14 hydro-

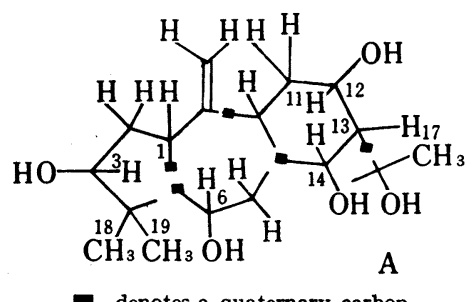

denotes a quaternary carbon gens, the $\mathrm{C}-3$ and $\mathrm{C}-18$ hydrogens, the $\mathrm{C}-3$ and $\mathrm{C}-19$ hydrogens, and the $\mathrm{C}-6$ and $\mathrm{C}-18$ hydrogens. Acetylation gave the triacetate (VIII) which on chromic acid oxidation yielded the ketone (IX) whose infrared (IR) spectrum indicated the formation of a cyclopentanone $\left(1727 \mathrm{~cm}^{-1}\right)$. Further the optical rotatory dispersion (ORD) and circular dichroism (CD) curves of the ketone (IX) $\left(a-34,[\theta]_{296}-2190\right)$ are similar to those of the ketone $(\mathrm{XI})$ derived from 
G-II 3,6-diacetate (X) $\left(a-49,[\theta]_{300}-2940\right)$. These data demonstrate that G-XI has the andromedane skeleton. The $\beta$-configuration of the $\mathrm{C}-12$ hydroxyl was deduced by the facts that 1) the $J_{11 \alpha, 12}, J_{11 \beta, 12}$ and $J_{12,13}$ are 6,10 , and $4 \mathrm{~Hz}$, respectively, and 2) the C-17 hydrogen signal shows considerable downfield shift $(-0.51 \mathrm{ppm})$ in comparison with that of G-II (VII). The combined evidence has led to the conclusion that G-XI has the stereostructure IV.

Acknowledgement We are grateful to Research Laboratories, Takeda Chemical Industries, Ltd., and to Analytical Laboratory, Department of Chemistry, this University, for NMR spectra.

\author{
Pharmaceutical Institute, \\ Tohoku University \\ Aobayama, Sendai
}

Received March 13, 1971

\author{
HiRoshi Hikino \\ TOMinisa OHTa \\ SHINII KORIYAMA \\ Yasuko Hikino \\ Tsunematsu TaKemoto
}

\section{Chemical Evidence for N-O Bond Fission in 4-Hydroxyaminoquinoline 1-0xide Formation of Pyrazino $\left[2,3-c: 5,6-c^{\prime}\right]$ biquinoline}

In the preceding communication ${ }^{1)}$ concerning with air oxidation of 4-hydroxyaminoquinoline 1-oxide (I) (4-HAQO) in basic solution, it has been reported that pyridazino[3,4-c:5,6-c']biquinoline were formed in free radical way. ${ }^{2-4}$. This paper deals with formation and its process of another type of biquinoline, pyrazino[2,3-c:5,6-c']biquinoline from 4-HAQO.

A suspension of 4 -HAQO in water was heated at $200-240^{\circ}$ for 3 hours in a sealed tube. Chloroform soluble layer of product was subjected to chromatography on silica gel to give a new dimer (II), $\mathrm{mp}>300^{\circ}, \mathrm{C}_{18} \mathrm{H}_{10} \mathrm{~N}_{4}$, UV $\lambda_{\max }^{\text {CHCls }} \mathrm{m} \mu(\varepsilon): 300(51300), 402(12100), 425(13800)$ and pyridazino $\left[3,4-c: 5,6-c^{\prime}\right]$ biquinoline(III) in 1.5 and $4.5 \%$ yield, respectively. The structure of II was confirmed to be pyrazino $\left[2,3-c: 5,6-c^{\prime}\right]$ biquinoline by comparison with an authentic sample prepared from 3-amino 4-chloroquinoline ${ }^{5)}$ as shown in Chart 1.

A research team of the National Cancer Center of Japan has reported ${ }^{6}$ that free radical was easily produced by the thermolysis of $\mathrm{O}, \mathrm{O}^{\prime}$-diacetyl 4-HAQO, probably because of the homolytic fission of $\mathrm{N}-\mathrm{O}$ bond between $\mathrm{O}$-acetyl and nitrogen, and further that the observed coupling constants of both nitrogen nuclei and a 3-position's proton were larger than those of other nucleis in ESR spectrum of the free radical. The report prompted us to propose plausible mechanisms as shown in Chart 2 for the formation of pyrazino- and pyridazinobiquinoline in the pyrolysis of 4-HAQO, since, it is reasonably considered that 4-HAQO at high temperature behaves as similar as its $\mathrm{O}, \mathrm{O}^{\prime}$-diacetate.

1) T. Kosuge, H. Zenda, and H. Sawanishi, Chem. Pharm. Bull. (Tokyo), 17, 2389 (1969).

2) C. Nagata, N. Kataoka, A. Imamura, Y. Kawazoe, and G. Chihara, Gann, 57, 323 (1966).

3) N. Kataoka, A. Imamura, Y. Kawazoe, G. Chihara, and C. Nagata, Bull. Chem. Soc. Japan, 40, 62 (1967).

4) N. Kataoka, S. Shibata, A. Imamura, Y. Kawazoe, G. Chihara, and C. Nagata, Chem. Pharm. Bull. (Tokyo), 15, 220 (1967).

5) A. R. Surry and R. A. Cutler, J. Am. Chem. Soc., 73, 2413 (1951).

6) M. Araki, Y. Kawazoe, and C. Nagata, Chem. Pharm. Bull. (Tokyo), 17, 1344 (1969). They also isolated

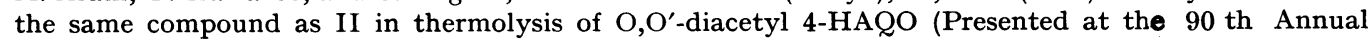
Meeting of the Pharmaceutical Society of Japan, Sapporo, July, 1970). 